ISSN: 2542-2812

Journal of Business and Social Sciences Research (JBSSR)

(The double blind, peer-reviewed journal of Ace Institute of Management)

\title{
Editorial
}

\section{Of the Change for the Better}

"The Only Thing That Is Constant Is Change."

$\sim$ Heraclitus

$\mathrm{T}$

he above quote not only inspires a lot of thoughts; but, more importantly, it should inspire a lot of actions. Many humans love change; and are leaders for change. It is, however, well documented that many other humans are resistant to change.

There are organisations that are growing steadily for a long period of time, until one such change makes things go obsolete and less effective. It is amazing to see how leaders cope up with change and are able to blossom in their own fields; and eventually bring about changes to their operations and outputs for the better. Thus, the dynamic leaders come out as triumphant: faster, smarter and better for change. That is the kind of attitude organisations and individuals need to strive for, in this competitive world. It is at the helm of affairs of the Journal of Business and Social Sciences Research (JBSSR) that editorial changes have been made. A few structural changes at the helm of editorial affairs accompanied by changes in editorial approaches have been introduced, hopefully for the better. We, at the editorial team of JBSSR, hope that the readers have a feel of positive 'change' in the output, for the better!

The publication of the new volume of JBSSR has come in reiteration of our commitment to research, as we strongly believe that a university or academic institute today needs to comprise 50 per cent teaching and 50 per cent research failing which it could cause substantial damage to the quality of education and learning. Four years on, the JBSSR has been going firm with its resilience from change, and committed to its regular publication.

Paper-contributors and the AIM authorities as well as the MBA (Masters in Business Administration) students of AIM deserve special thanks for making this publication possible. We sincerely believe that the readers and subscribers will find this issue informative and interesting. We look forward to constructive feedback from our valued readers and academic research fraternity.

- Prof. Arhan Sthapit, $P h D$ Chief Editor 